\title{
Journal of Bacteriology and

Prevalence and Antimicrobial Susceptibility of Methicillin-Resistant Staphylococcus aureus (MRSA) from Outpatients with Chronic Rhinosinusitis in Al-Kut/Wasit Province/Iraq

\author{
Sareaa MG Al-Mayahie ${ }^{1^{*}}$, Hiba TR AI- Hamashee ${ }^{1}$ and Husam M Hameed ${ }^{2,3}$ \\ ${ }^{1}$ Department of Biology, College of Science, University of Wasit, Al-Kut, Wasit Province, Iraq \\ ${ }^{2}$ Department of Surgery, College of Medicine, University of Wasit, Al-Kut, Wasit Province, Iraq \\ ${ }^{3} D$ AL Karama Teaching Hospital, Al-Kut, Wasit Province, Iraq
}

*Corresponding author: Sareaa MG Al-Mayahie, Department of Biology, College of Science, University of Wasit , Al-Kut, Wasit Province, Iraq, Tel: 096407802833209; E-mail: sareaamaseer@yahoo.com

Received date: May 04, 2015; Accepted date: June 17, 2015; Published date: June 22, 2015

Copyright: @ 2015 Al-Mayahie, et al. This is an open-access article distributed under the terms of the Creative Commons Attribution License, which permits unrestricted use, distribution, and reproduction in any medium, provided the original author and source are credited.

\begin{abstract}
Staphylococcus aureus is a significant factor in the development of chronic rhinosinusitis (CRS). Prevalence of sinonasal methicillin-resistant $S$. aureus (MRSA) appears to be increasing among CRS patients. For that this study was designed to detect the prevalence and antimicrobial resistance of MRSA isolates from Iraqi patients with CRS living in Al-Kut city/Wasit Province. Out of 264 patients with CRS, S. aureus was isolated from 71 (one isolate per patient) $(26.8 \%)$. Of these patients, $37(52.1 \%)$ were females (age range 2 months to 61 year) and $34(47.8 \%)$ were males (age range 3 to 70 year). Fifty two $(73.2 \%)$ of $S$. aureus isolates were MRSA, of which $71.1 \%$ were mecApositive. Distribution of MRSA was significantly $(P \leq 0.05)$ associated with patient's age, whereas it was insignificantly associated with patient's gender. The highest resistance rates of MRSA were against $\beta$-lactams except carbapenems, whereas the highest susceptibility was for vancomycin, followed by imipenem, genatmycin, meropenem and ciprofloxacin. Twenty two (30.9\%) isolates were multidrug resistant (MDR), of which $20(28.1 \%)$ were MRSA and $2(2.8 \%)$ were methicillin-sensitive S. aureus (MSSA). No isolate showed resistance or sensitivity to all antimicrobials included in this study. Highest rate of multidrug resistance was to 13 antimicrobials (1 isolate which was MRSA), whereas the lowest rate was to 6 antimicrobials ( 3 isolates which were MRSA).
\end{abstract}

Conclusions: These results indicate the high prevalence of MRSA among Iraqi patients with CRS and reveal its predominance in our community. Furthermore, high percentage of these isolates were MDR, which urge us to reevaluate the empiric treatment of these cases.

Keywords: MRSA; CRS; Prevalence; Antimicrobial resistance

\section{Introduction}

Chronic rhinosinusitis (CRS) is an inflammation of the nose and sinuses in which the signs and symptoms last for more than 12 weeks and characterize by nasal blockage/obstruction/congestion, nasal discharge, facial pain, and/or reduction of smell [1]. Cases of CRS are subdivided into cases with polyps (CRSwNP) and cases without polyps (CRSwtNP) [2]. Chronic rhinosinusitis represents a multifactorial inflammatory disorder, rather than simply a persistent bacterial infection [3]. Staphylococcus aureus and anaerobic bacteria are the main isolates in chronic sinusitis [4].

In healthy subjects the sinuses are nonsterile environments that are colonized with aerobic and anaerobic bacteria, including $S$. aureus [4]. Staphlococcus aureus colonization rates have been found to be around $33.3 \%$ and $27.3 \%$ in healthy individuals and in patients with CRS, respectively [2]. Others [5] reported that $S$. aureus isolation rates in CRS patients range from $15 \%$ to $70 \%$. Furthermore, it was suggested that $S$. aureus is a significant factor in the development of CRS $[6,7]$. Increased recovery rate of methicillin-resistant $S$. aureus (MRSA) in patients with upper respiratory tract infections, including acute and chronic maxillary sinusitis, was reported $[8,4]$, so that incidence of MRSA in these patients is becoming a clinical concern [9]. Methicillin- resistant $S$. aureus (MRSA) is any strain of $S$. aureus that is resistant to all $\beta$-lactams due to acquisition of a transpeptidase, PBP2a, involved in cell wall synthesis that has low affinity for $\beta$-lactam antibiotics. This PBP2a is encoded by mecA gene. This gene is complex, contains insertion sites for plasmids and transposons that facilitate acquisition of resistance to other antibiotics (multidrug resistance: MDR), hence there is restricted number of treatment choices for infections caused by MRSA [10]. Sinonasal infection caused by MRSA usually treated by a combination of oral and topical antibiotics for 1 to 2 weeks. Trimethoprim/sulfamethoxazole or clindamycin are usually used orally. While intravenous antibiotics are limited to severe infections $[11,12]$.

Prevalence of sinonasal MRSA appears to be increasing, and many unanswered questions remain regarding its role in sinonasal infection and its treatment $[4,9]$. Furthermore, the risk of MRSA presence in the infected sinus may not only lead to failure of antimicrobial therapy, but may also serve as a source for the spread of these organisms to other body sites, as well as an origin for dissemination to other individuals [13]. So that the sooner an MRSA infection is diagnosed, and the susceptibility to antimicrobial agents established, the sooner appropriate therapy and control measures are crucial steps in treating, controlling, and preventing MRSA infections [14]. In addition, as a result of changing resistance profiles of these bacteria, empiric treatment options need to be evaluated [15]. In Iraq, several studies 
Citation: Al-Mayahie SMG, Al- Hamashee HTR, Hameed HM (2015) Prevalence and Antimicrobial Susceptibility of Methicillin-Resistant Staphylococcus aureus (MRSA) from Outpatients with Chronic Rhinosinusitis in Al-Kut/Wasit Province/lraq. J Bacteriol Parasitol 6: 230. doi:10.4172/2155-9597.1000230

Page 2 of 6

were carried out regarding the prevalence and antimicrobial resistance of MRSA from different clinical materials, but little is known about these bacteria in patients with CRS. For that this study was designed to detect the prevalence and antimicrobial resistance pattern of MRSA isolates from Iraqi patients with CRS living in Al-Kut city/ Wasit Province, using phenotypic and genotypic protocols.

\section{Materials and Methods}

\section{Definition and diagnosis of CRS}

Chronic rhinosinusitis can be defined as inflammation of the nose and paranasal sinuses with persistence of signs and symptoms for 12 weeks and more without total cure. The diagnosis of CRS depended on the above definition in addition to findings of two major factors, or one major and two minor factors [1] as follows: after full ENT history and examination the diagnosis of CRS was done according to the symptoms \& signs that are characteristics of CRS. Major symptoms include: facial pain/pressure; facial congestion/fullness; nasal obstruction/blockage; nasal discharge/purulence/discoloured; posterior drainage; hyposomia/anosmia; purulence on nasal examination and fever (acute RS only). Whereas minor symptoms are: headache; fever (nonacute); halitosis; fatigue; dental pain; cough; and ear pain/pressure. The diagnosis was confirmed by flexible nasopharyngoscopy to find signs of CRS like oedema, polypoidal mucosa, mucopus in the middle turbinate or mucopurulent discharge in the postnasal space around the Eustachian tube.

\section{Patients}

This study included 264 (150 females and 114 males) patients with CRS aged 2 months to 82 years. They were outpatients attending Otolaryngology clinic in Al-Kut City/Wasit Province/Iraq. History of antibiotic usage was documented. Some of the patients were on antibiotic treatment with amoxicillin for 1 to 2 days before specimen collection.

This work was approved by Wasit Health Administration/Wasit Province/Iraq. Also, all bacterial isolates in this study were collected and analysed anonymously. Therefore, consent from the patient was not required.

\section{Specimen collection and processing}

Specimens were collected during October 1st, 2013 to April 30th, 2014. Each patient had a specimen collected from the nares with a dry, unmoistened swab. The tip of the collection swab was inserted approximately $2.56 \mathrm{~cm}$ into the nares and rolled five times in each nostril. Collected specimens were inoculated directly onto mannitol salt agar plates (Oxoid) that were incubated for 24 to $48 \mathrm{~h}$ at $35^{\circ} \mathrm{C}$ and examined for growth and mannitol fermentation [16].

\section{Identification of $S$. aureus species}

Isolates that produced yellow colonies on mannitol salt agar screen were primarily identified as Staphylococcus spp. by colony mophology and pigmentation on tryptic soy agar, Gram stain, and catalase test. Biochemical identification of $S$. aureus was based on tube coagulase and hemolysin production [17].

Also all mannitol fermenting isolates were subjected to species identification by PCR protocol according to Ruzickova et al. [18]. Each isolate was subcultured on tryptic soy agar plates for $24 \mathrm{~h}$ at $37^{\circ} \mathrm{C}$.
From the agar plate a loopfull was taken and suspended in $88 \mu \mathrm{l}$ sterile distilled water, then $10 \mu \mathrm{l}$ of extraction buffer and $2 \mu \mathrm{l}$ of extraction enzyme were added according to the manuacturer's instructions (KAPA Express Extract, KAPA Biosystm, USA). Bacterial suspensions were run for $10 \mathrm{~min}$ at $75^{\circ} \mathrm{C}$, followed by $5 \mathrm{~min}$ at $95^{\circ} \mathrm{C}$ in a DNA thermocycler (MultiGene, Labnet International, Inc., USA) and cell debris were removed by centrifugation (12,000 rpm for $1 \mathrm{~min})$. Five $\mu \mathrm{l}$ of supernatant was used as a template DNA in PCR. Genomic DNA of bacterial isolates was amplified by PCR using primers targeted to conserved $S$. aureus sequence (SAU-JIRS10: F:5'-ATA AGA GAT GGC GGT ACT AAA -3' and SAU-JIRS11: R:5'-TAA GGC GGA TTA CAC GTT ACT -3', with amplicon size of $532 \mathrm{bp}$ ). PCR amplification reactions were performed in a final volume of $25 \mu$ containing lyophlized Mastermix (AccuPowder PCR PreMix, Bioneer, Korea) dissolved in sterile distilled water, 20 pmol concentrations of each primer and $5 \mu \mathrm{l}$ of DNA template. The cycling parameters were as follows: an initial denaturation at $94^{\circ} \mathrm{C}$ for $4 \mathrm{~min}$; followed by 25 cycles of $94^{\circ} \mathrm{C}$ for $30 \mathrm{~s}, 54^{\circ} \mathrm{C}$ for $30 \mathrm{~s}$, and $70^{\circ} \mathrm{C}$ for $90 \mathrm{~s}$; and with a final extension at $72^{\circ} \mathrm{C}$ for $7 \mathrm{~min}$. The amplified PCR products were subjected to electrophoresis at a $2 \%$ agarose gel in $0.5 \mathrm{X}$ TBE buffer.

\section{Phenotypic screening for methicillin resistance}

Detection of MRSA was carried out using oxacillin screen agar and cefoxitin disc diffusion test according to CLSI instructions [19].

\section{Oxacillin screen agar}

Mueller-Hinton agar (MHA) plates containing $4 \% \mathrm{NaCl}$ and 6 $\mu \mathrm{g} / \mathrm{ml}$ of oxacillin (Sigma, USA) were prepared. Plates were inoculated with $10 \mu \mathrm{L}$ of $0.5 \mathrm{McF}$ arland suspension of the isolate by streaking in one quadrant and incubated at $35^{\circ} \mathrm{C}$ for $24 \mathrm{~h}$. Plates were observed carefully in transmitted light for any growth. Any growth after $24 \mathrm{~h}$ was considered oxacillin resistant.

\section{Cefoxitin disc diffusion test}

All the isolates were subjected to cefoxitin disc diffusion test using a $30 \mu \mathrm{g}$ disc (Bioanalyse). A $0.5 \mathrm{McF}$ arland standard suspension of the isolate was made and lawn culture done on MHA plate. Plates were incubated at $37^{\circ} \mathrm{C}$ for $18 \mathrm{~h}$ and zone diameters were measured. An inhibition zone diameter of $\leq 21 \mathrm{~mm}$ was reported as oxacillin resistant and $\geq 22 \mathrm{~mm}$ was considered as oxacillin sensitive.

\section{Genotypic screening for methicillin resistance (PCR amplification for detection of mec $A$ gene)}

All $S$. aureus isolates were screened for $m e c A$ gene by PCR. The $m e c A$ gene was amplified using primers as described by Murakami et al. [20] (F:5' AAA ATC GAT GGT AAA GGT TGG C 3', R: 5' AGT TCT GCA GTA CCG GAT TTG C 3'). PCR amplification reactions were performed in a final volume of $25 \mu$ l containing lyophlized Master mix (AccuPowder PCR PreMix, Bioneer, Korea) dissolved in sterile distilled water, 20 pmol concentrations of forward and reverse primers and $5 \mu \mathrm{l}$ of DNA template. The cycling parameters were as follows: an initial denaturation at $94^{\circ} \mathrm{C}$ for $5 \mathrm{~min}$; followed by 40 cycles of $94^{\circ} \mathrm{C}$ for $30 \mathrm{~s}, 55^{\circ} \mathrm{C}$ for $30 \mathrm{~s}$, and $70^{\circ} \mathrm{C}$ for $1 \mathrm{~min}$; and with a final extension at $72^{\circ} \mathrm{C}$ for $5 \mathrm{~min}$. PCR products were visualized on $2 \%$ agarose gel with ethidium bromide dye under UV transilluminator. Amplicons of 533 bp were consistent with mecA gene amplification. 
Citation: Al-Mayahie SMG, Al- Hamashee HTR, Hameed HM (2015) Prevalence and Antimicrobial Susceptibility of Methicillin-Resistant Staphylococcus aureus (MRSA) from Outpatients with Chronic Rhinosinusitis in Al-Kut/Wasit Province/lraq. J Bacteriol Parasitol 6: 230. doi:10.4172/2155-9597.1000230

Page 3 of 6

\section{Susceptibility testing}

Disk-diffusion tests were carried out with antibiotic-containing disks (Bioanalyse) on Mueller-Hinton agar plate (Himedia). The results were expressed as susceptible or resistant according to the criteria recommended by CLSI [19]. The following antimicrobial agents were tested: $\beta$-lactms [penicillin (P: $10 \mathrm{IU})$, amoxicillin (AX: 25 $\mu \mathrm{g}$ ), amoxicillin-clavulanic acid (AMC: $20 / 10 \mu \mathrm{g}$ ), cefoxitin (FOX: 30 $\mu \mathrm{g}$ ), cefotaxime (CTX: $30 \mu \mathrm{g}$ ), ceftazidime (CAZ: $30 \mu \mathrm{g}$ ), ceftriaxone (CRO: $30 \mu \mathrm{g}$ ), imipenem (IMP: $10 \mu \mathrm{g}$ ), and meropenem (MEM: 10 $\mu \mathrm{g}$ )], macrolides [clindamycin (DA: $10 \mu \mathrm{g}$ ), azithromycin (AZM: 15 $\mu \mathrm{g}$ ) and clarthromycin (CLR: 15)], polypeptides [vancomicin (VA: 30 $\mu \mathrm{g}$ )], sulfonamides [trimethoprim-sulfomethoxazole (SXT: 1.25/23.75 $\mu \mathrm{g})$, fluoroquinolones [ciprofloxacin (CIP: $5 \mu \mathrm{g})$ ], and aminoglycosides [gentamicin (CN: $10 \mu \mathrm{g})$ and amikacin (AK: $10 \mu \mathrm{g})$ ].

\section{Statistical analysis}

Differences in the distributions of the studied determinants were tested by Chi square [21]. A P value of $\leq 0.05$ was considered to indicate statistical significance.

\section{Results}

\section{Prevalence of MRSA among CRS patients}

Staphylococcus aureus was isolated from 71 (one isolate per patient) out of 264 (26.8\%) patients with CRS. Of these patients, 37 (52.1\%) were females (age range 2 months to 61 years) and 34 (47.8\%) were males (age range 3 to 70 years).

Fifty two (73.2\%) S. aureus isolates were oxacillin resistant (MRSA) by screen test. mecA-mediated oxacillin resistance among these isolates was noted in 37 isolates $(71.1 \%)$ by both cefoxitin disc diffusion and PCR tests.

As a whole, distribution of MRSA was significantly $(\mathrm{P} \leq 0.05)$ associated with patient's age. The highest rate of MRSA isolation was in the young age groups (11-20 and 21-30 year) in both females $(26.9 \%$ vs. $42.3 \%$, respectively) and males (23.0\% vs. $30.7 \%$, respectively) (Table 1). Whereas the isolation rate of MRSA was similar in females and males (50\% each). So that prevalence of MRSA was insignificantly associated to the patient's gender.

\begin{tabular}{|c|c|c|c|c|c|c|c|c|c|}
\hline \multirow{3}{*}{$\begin{array}{l}\text { Patient's age } \\
\text { (year) }\end{array}$} & \multicolumn{9}{|c|}{ No. of S. aureus isolates (\%) } \\
\hline & \multicolumn{3}{|c|}{ MSSA } & \multicolumn{3}{|c|}{ MRSA } & \multicolumn{3}{|c|}{ Total } \\
\hline & $\begin{array}{l}\text { Females } \\
(n=11)\end{array}$ & $\begin{array}{l}\text { Males } \\
(n=8)\end{array}$ & $\begin{array}{l}\text { Total } \\
(\mathrm{n}=19)\end{array}$ & $\begin{array}{l}\text { Females } \\
(n=26)\end{array}$ & $\begin{array}{l}\text { Males } \\
(n=26)\end{array}$ & $\begin{array}{l}\text { Total } \\
(\mathrm{n}=52)\end{array}$ & $\begin{array}{l}\text { Females } \\
(n=37)\end{array}$ & $\begin{array}{l}\text { Males } \\
(\mathrm{n}=34)\end{array}$ & $\begin{array}{l}\text { Total } \\
(\mathrm{n}=71)\end{array}$ \\
\hline$\leq 10$ & $\begin{array}{l}1 \\
(9.0)\end{array}$ & $1(12.5)$ & $2(10.5)$ & $\begin{array}{l}1 \\
(3.8)\end{array}$ & $4(15.3)$ & $\begin{array}{l}5 \\
(9.6)\end{array}$ & $\begin{array}{l}2 \\
(5.4)\end{array}$ & $\begin{array}{l}5 \\
(14.7)\end{array}$ & $\begin{array}{l}7 \\
(9.8)\end{array}$ \\
\hline $11-20$ & $\begin{array}{l}3 \\
(27.2)\end{array}$ & $\begin{array}{l}1 \\
(12.5)\end{array}$ & $4(21.0)$ & $\begin{array}{l}7 \\
(26.9)\end{array}$ & $6(23.0)$ & $13(25.0)$ & $10(27.0)$ & $\begin{array}{l}7 \\
(20.5)\end{array}$ & $17(23.9)$ \\
\hline $21-30$ & $\begin{array}{l}2 \\
(18.1)\end{array}$ & $3(37.5)$ & $5(26.3)$ & $11(42.3)$ & $8(30.7)$ & $19(36.5)$ & $13(35.1)$ & $11(32.3)$ & $24(33.8)$ \\
\hline $31-40$ & $\begin{array}{l}1 \\
(9.0)\end{array}$ & 0 & $\begin{array}{l}1 \\
(5.2)\end{array}$ & $\begin{array}{l}3 \\
(11.5)\end{array}$ & $\begin{array}{l}1 \\
(3.8)\end{array}$ & $\begin{array}{l}4 \\
(7.6)\end{array}$ & $\begin{array}{l}4 \\
(10.8)\end{array}$ & $\begin{array}{l}1 \\
(2.9)\end{array}$ & $\begin{array}{l}5 \\
(7.0)\end{array}$ \\
\hline $41-50$ & 0 & $\begin{array}{l}1 \\
(12.5)\end{array}$ & $\begin{array}{l}1 \\
(5.2)\end{array}$ & $\begin{array}{l}2 \\
(7.6)\end{array}$ & $\begin{array}{l}2 \\
(7.6)\end{array}$ & $\begin{array}{l}4 \\
(7.6)\end{array}$ & $\begin{array}{l}2 \\
(5.4)\end{array}$ & $\begin{array}{l}3 \\
(8.8)\end{array}$ & $\begin{array}{l}5 \\
(7.0)\end{array}$ \\
\hline $51-60$ & $\begin{array}{l}4 \\
(36.3)\end{array}$ & $\begin{array}{l}1 \\
(12.5)\end{array}$ & $\begin{array}{l}5 \\
(26.3)\end{array}$ & $\begin{array}{l}1 \\
(3.8)\end{array}$ & $\begin{array}{l}2 \\
(7.6)\end{array}$ & $\begin{array}{l}3 \\
(5.7)\end{array}$ & $\begin{array}{l}5 \\
(13.5)\end{array}$ & $\begin{array}{l}3 \\
(8.8)\end{array}$ & $\begin{array}{l}8 \\
(11.2)\end{array}$ \\
\hline$\geq 60$ & 0 & $\begin{array}{l}1 \\
(12.5)\end{array}$ & $\begin{array}{l}1 \\
(5.2)\end{array}$ & $\begin{array}{l}1 \\
(3.8)\end{array}$ & $3(11.5)$ & $\begin{array}{l}4 \\
(7.6)\end{array}$ & $\begin{array}{l}1 \\
(2.7)\end{array}$ & $\begin{array}{l}4 \\
(11.7)\end{array}$ & $\begin{array}{l}5 \\
(7.0)\end{array}$ \\
\hline Total & 11 & 8 & 19 & 26 & 26 & 52 & 37 & 34 & 71 \\
\hline
\end{tabular}

Table 1: Distribution of $S$. aureus isolates among patients with CRS according to patient's gender and age.

\section{Antimicrobial susceptibility of MRSA}

All $S$. aureus isolates were subjected to antimicrobial susceptibility test against 17 antimicrobial drugs referred to 6 classes. All of $S$. aureus isolates were sensitive to vancomycin $(100 \%)$ followed by imipenem (98.5\%), Gentamycin (95.7\%), meropenem (91.5\%), and ciprofloxacin $(83.0 \%)$ (Figure 1). However, only one isolate was sensitive to penicillin. Accordingly, the highest resistance (including resistant and intermediate resistant) was observed for penicillin (98.5\%), followed by amoxicillin $(95.8 \%)$, ceftriaxone $(94.2 \%)$, ceftazidime $(80.2 \%)$, cefotaxime (76.0\%), amoxicillin-clavulante (59.1\%), azithromycin $(56.3 \%)$, amikacin $(53.4 \%)$, cefoxitin $(52.1 \%)$, clindamycin $(49.2 \%)$ and trimethoprim-sulfomethoxazole (42.2\%).

For all antimicrobials included in this study resistance rate of MRSA was higher than that of MSSA (Figure 1). All (100\%) isolates of MRSA were resistant to both penicillin and amoxicillin followed by ceftriaxone (94.1\%), cefotaxime (92.3\%), ceftazidime (84.5\%), cefoxitin (71.1\%), amoxicillin-clavulanate (63.4\%), azithromycin (61.4\%), amikacin (59.6\%), clarthromycin (57.6\%), trimethoprim- 
Citation: Al-Mayahie SMG, Al- Hamashee HTR, Hameed HM (2015) Prevalence and Antimicrobial Susceptibility of Methicillin-Resistant Staphylococcus aureus (MRSA) from Outpatients with Chronic Rhinosinusitis in Al-Kut/Wasit Province/lraq. J Bacteriol Parasitol 6: 230. doi:10.4172/2155-9597.1000230

Page 4 of 6

sulfamethoxazole $(50.0 \%)$. and clindamycin (46.1\%). On the other hand, the highest susceptibility of MRSA was observed for vancomycin (100\%), followed by imipenem (98.0\%), genatmycin $(94.2 \%)$, meropenem (90.3\%), and ciprofloxacin (82.6\%).

Twenty two (30.9\%) isolates were MDR, of which 20 (28.1\%) were MRSA and $2(2.8 \%)$ were MSSA. No isolate showed resistance or sensitivity to all antimicrobials included in this study. Highest rate of multidrug resistance was to 13 antimicrobials (1 isolate which was MRSA), whereas the lowest rate was to 6 antimicrobials (3 isolates which were MRSA) (Table 2).

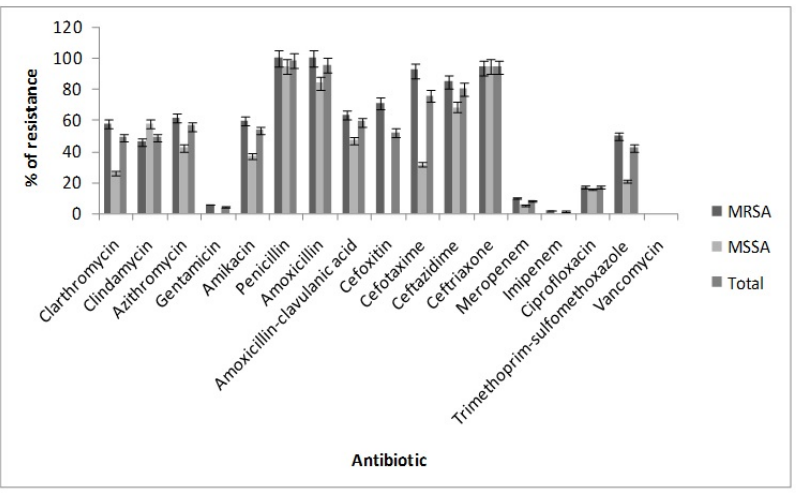

Figure 1: Percentages of antimicrobial resistance of $71 \mathrm{~S}$. aureus isolates from patients with CRS.

\section{Discussion}

Chronic rhinosinusitis remains a highly prevalent disease with a major impact on overall quality of life [12]. Previous investigations $[8,9]$ suggested that there is a significant etiological role of MRSA in CRS to which there is restricted number of treatment choices [15]. Therefore, we investigated prevalence and antimicrobial resistance of MRSA isolates from Iraqi patients with CRS. In this study, $S$. aureus was isolated from $26.8 \%$ of outpatients with CRS, of these isolates $73.2 \%$ were MRSA. Similar figures were reported from other parts of Iraq among patients with different clinical cases other than CRS. In the western city Ramadi, Lafi et al. [22] demonstrated MRSA in $73.1 \%$ of $S$. aureus isolates from blood culture and wound swabs. Also, in north Iraq, Mohammed [23] isolated MRSA in frequency of $72.0 \%$ from the nose of health work staff in surgery unit of Kalar General Hospital and from ear of patients attended to the same hospital. In Baghdad, it was found that $55.5 \%$ of $S$. aureus isolates from urinary tract infection (UTI) patients were MRSA [24]. High isolation percentages of MRSA from CRS patients were demonstrated in other parts of the world as in the USA where Brook et al. [8] compared the rate of recovery of MRSA between the periods 2001-2003 and 2004-2006. They found $S$. aureus in $15 \%$ of the patients with CRS between 2001 and $2003,27 \%$ of which were MRSA, whereas during the period from 2004-2006 $S$. aureus was found in $20 \%$ of the patients with CRS, $61 \%$ of which were MRSA. In Nigeria, Ologe \& Nwabuisi [25] demonstrated $S$. aureus in $47.1 \%$ of CRS patients. Also, Niederfuhr et al. [26] isolated $S$. aureus from $23.0 \%$, and $38.7 \%$ of patients with CRS without and with nasal polyp, respectively. Our results and those of above mentioned workers reveal the significant increase in the rate of recovery of MRSA from patients with CRS. This may reflect the irrational and intensive use of antimicrobial agents, especially $\beta$-lactams, in our community, as $\beta$ lactam antibiotics represent a selective pressure favor the selection and emergence of the mutant strains which express homogeneous resistance $[23,27]$. Others $[8,28]$ reported that previous antibiotic treatment seems to be a risk factor for CRS infection with MRSA, as they isolated MRSA more often from treated individuals than from those not treated previously. This indicates a possible role for antibiotic usage to the emergence of MRSA-causing CRS [29]. Furthermore, Didier et al. [30] and Sachithanandam [28] explained the high prevalence of multiresistant MRSA by intensive use of topical and systemic antimicrobial agents which represent a highly selective pressure for antibiotic-resistant bacterial clones. In addition, bacterial exposure to some antibiotic classes may potentially induce endogenous, resistance-conferring mutations in bacterial genes that encode drug targets.

In both females and males distribution of MRSA was significantly $(P \leq 0.05)$ associated with the patient's age where the highest rate of MRSA isolation was in the young age groups (11-20 and 21-30 year) in both females and males. Whereas the prevalence of MRSA was insignificantly associated to the patient's gender. These results were in partial agreement with Brook et al. [8] who found no differences in the age distribution, ethnicity or gender of the patients. Also, Niederfuhr et al. [26] reported that $S$. aureus detection rates were not influenced by gender, atopic state, or presence of asthma. Although the age distribution of MRSA was significantly different, our estimation may be not real as the number of patients at different age groups was not equal. About half of patients (127/264: 48.1\%) were at the young age groups (11-20 and 21-30 year) in both females and males.

Overall resistance patterns of MRSA isolates included in this study were consistent with those obtained by other Iraqi researchers [23,31], where the highest resistance rates were against $\beta$-lactam antibiotics, except carbapenems. These high resistance rates were expected as most MRSA isolates in this study were mecA producers (71.1\%). Our results were consistent with other researchers in Iraq $[23,31]$ and across the world $[4,10,12,14,19]$ where the most clinically important resistance mechanism in staphylococcal isolates to $\beta$-lactam antimicrobials is the acquisition of a mecA gene encoding a modified penicillin-binding protein (PBP), known as PBP2a. This PBP2a is intrinsically resistant to inhibition by $\beta$-lactams $[10,14]$. In addition, $\operatorname{mec} A$-negative MRSA have another mechanisms of methicillin resistance, such as changes in affinity of PBPs for oxacillin $[14,19]$. Lack of control over antibiotic use in our country is the main reason for the development of increasing resistance to different antimicrobials among our clinical isolates including MRSA. Also, overuse of $\beta$-lactams for treating different cases in our hospitals is another reason for this high prevalence of MRSA. Emergence of antibiotic-resistant bacterial clones reflects the intensive use of antimicrobial agents [30]. So that there must be a scheduled rotation of $\beta$-lactams use with other antimicrobials in the study area to reduce this high antibiotic resistance among our isolates.

Amoxicillin-clavulanate, clindamycin, trimethoprim/ sulfamethoxazole, and levofloxacin or ciprofloxacin represent the commonly used agents for treatment of CRS caused by MRSA [12]. In the study area, amoxicillin- clavulanate, cefoxitin, cefotaxime, ceftriaxone and trimethoprim-sulfamethoxazole were the most commonly used antimicrobials for treatment of CRS patients as explained by Otolaryngologists. In this study resistance of MRSA to these antimicrobials were $63.4 \%, 71.1 \%, 92.3 \%, 94.2 \%$ and $50.0 \%$, respectively. Also, $46.1 \%$ of MRSA were resistant to clindamycin. 
Citation: Al-Mayahie SMG, Al- Hamashee HTR, Hameed HM (2015) Prevalence and Antimicrobial Susceptibility of Methicillin-Resistant Staphylococcus aureus (MRSA) from Outpatients with Chronic Rhinosinusitis in Al-Kut/Wasit Province/lraq. J Bacteriol Parasitol 6: 230. doi:10.4172/2155-9597.1000230

Page 5 of 6

Whereas $11.5 \%$ were resistant to ciprofloxacin. So that ciprofloxacin is most appropriate antimicrobial for treating CRS patients in the study area. For isolates that are resistant to ciprofloxacin the suitable alternative is gentamicin, since $3.8 \%$ of MRSA isolates were resistant to this antimicrobial. Amoxicillin-clavulanate, clindamycin, cefoxitin, cefotaxime, ceftriaxone and trimethoprim-sulfamethoxazole must be stopped in order to prevent distribution of resistance among $S$. aureus isolates. Gilmore et al. [10] reviewed that reduction of antibiotic use within the hospital could decrease nosocomial acquisition of multiresistant bacteria, in addition to scheduled rotation of antibiotic use. Furthermore, strict compliance with infection control policies can aid in the reduction of nosocomial spread of multidrug-resistant MRSA.

\begin{tabular}{|l|l|l|}
\hline \multirow{2}{*}{ Resistance pattern } & \multicolumn{2}{|l|}{$\begin{array}{l}\text { No. (\%) } \\
\text { aureus }\end{array}$} \\
\cline { 2 - 3 } & $\begin{array}{l}\text { MRSA } \\
\text { (n=20) }\end{array}$ & $\begin{array}{l}\text { MSSA } \\
\text { (n=2) }\end{array}$ \\
\hline $\begin{array}{l}\text { P, AX, AMC, FOX, OX, CTX, CAZ, CRO, CLR, DA, AZM, } \\
\text { SXT, AK }\end{array}$ & $1(5.0)$ & 0 \\
\hline P, AX, AMC, FOX, OX, CTX, CAZ, CLR, DA, AZM, SXT & $1(5.0)$ & 0 \\
\hline P, AX, AMC, FOX, CTX, CAZ, CRO, CLR, AZM, SXT, AK & $1(5.0)$ & 0 \\
\hline P, AX, AMC, FOX, CTX, CAZ, CRO, CLR, AZM, CN, AK & $1(5.0)$ & 0 \\
\hline P, AX, AMC, FOX, CTX, CAZ, CRO, CLR, DA, AZM, CIP & $1(5.0)$ & 0 \\
\hline P, AX, AMC, OX, CTX, CRO, CLR, DA, AZM, SXT & $2(10.0)$ & 0 \\
\hline P, AX, FOX, OX, CTX, CRO, CLR, DA, AZM, SXT & $1(5.0)$ & 0 \\
\hline P, AX, AMC, OX, CTX, CAZ, CRO, CLR, AZM, SXT & 0 & $1(50.0)$ \\
\hline P, AX, AMC, FOX, OX, CRO, CLR, AZM, AK, CIP & $1(5.0)$ & 0 \\
\hline P, AX, AMC, FOX, OX, CTX, CAZ, CRO, SXT, CIP & $1(5.0)$ & 0 \\
\hline P, AX, OX, CTX, CRO, CLR, DA, AZM, SXT & $4(20.0)$ & 0 \\
\hline P, AX, FOX, OX, CLR, DA, AZM, SXT & $1(5.0)$ & 0 \\
\hline P, AX, AMC, CLR, DA, AZM, SXT, CIP & 0 & $1(50.0)$ \\
\hline P, FOX, CRO, CLR, DA, AZM, CIP & $1(5.0)$ & 0 \\
\hline P, AX, OX, CLR, DA, AZM, SXT & $1(5.0)$ & 0 \\
\hline P, AX, FOX, CRO, SXT, AK & $1(5.0)$ & 0 \\
\hline P, OX, CLR, DA, AZM, AK & $1(5.0)$ & 0 \\
\hline P, OX, CLR, DA, AZM, SXT & $1(5.0)$ & 0 \\
\hline
\end{tabular}

Table 2: Antimicrobial resistance patterns of multidrug resistant $S$. aureus isolates from patients with CRS.

For all antimicrobials included in this study resistance rate of MRSA was higher than that of MSSA. Also, 38.4\% (20/52) of MRSA were MDR compared to $10.5 \%$ (2/19) of MSSA. Cross-resistance of MRSA to other antibiotics (in addition to their resistance to $\beta$-lactams) is due to mecA and its associated DNA which act as a trap for integration of other determinants, including genes for resistance to fluoroquinolones, aminoglycosides, tetracyclines, macrolides, trimethoprim-sulfamethoxazole and erythromycin [10,14,15]. Also, many MDR MRSA strains are presently only susceptible to a single class of clinically available bactericidal antibiotic, the glycopeptides (vancomycin and teicoplanin), and the widespread acquisition of the $\operatorname{van} A$ or $\operatorname{van} B$ determinants from enterococci would be a potential public health disaster [10]. All our $S$. aureus isolates (MRSA and MSSA) were sensitive to vancomycin which is not used for treatment of CRS patients in the study area. In other parts of Iraq, it was found that $92.0 \%$ [23] and $100 \%$ [31] of MRSA isolates were sensitive to vancomycin. So that vancomycin may be a drug of choice for serious cases caused by MDR MRSA. In the light of our results there is an obvious need for more effective antibiotic therapy for infections with MRSA. However, new therapeutic agents alone will not provide a long-term solution, and our attention to prevention must remain constant. Strict adherence to hospital infection-control practices, as well as appropriate use of antibiotics and improved surveillance systems to track the emergence of resistance patterns, are of primary importance as we look to the future usefulness of antibiotic therapy against this extremely adaptive organism [10].

\section{Conclusions}

Methicillin-resistant $S$. aureus had high prevalence among Iraqi outpatients with CRS, which indicate their predominance in our community. Furthermore, a significant percentage of these isolates were MDR, which urge us to reevaluate the empiric treatment of these cases.

\section{Acknowledgments}

We are grateful to the college of Science/ Wasit University for supporting this research.

\section{References}

1. Benninger MS (2008) Rhinosinusitis (chapter 113). In: Gleeson M (ed.) Scott-Brown's Otorhinolaryngology, Head and Neck Surgery (7thedn.) 3 volume set. CRC Press, London. pp. 1439-1448.

2. Derycke L, Pe'rez-Novo C, Crombruggen KV, Corriveau MN, Bachert C (2010) Staphylococcus aureus and chronic airway disease. World Allergy Organ J 3: 223-228.

3. Leung RS, Katial R (2008) The diagnosis and management of acute and chronic sinusitis. 35: 11-24.

4. Brook I (2011) Microbiology of sinusitis. Proc Am Thorac Soc 8: 90-100.

5. Lin A, Busaba NY (2006) Staphylococcus aureus and endoscopic sinus surgery. Curr Opin Otolaryngol Head Neck Surg 14: 19-22.

6. Tripathi A, Kern R, Conley DB, Seiberling K, Klemens JC, et al. (2005) Staphylococcal exotoxins and nasal polyposis: analysis of systemic and local responses. Am J Rhinol 19: 327-333.

7. Batchers C, Zhang N, van Zele T, Gevaert P, Patou J, et al. (2007) Staphylococcus aureus enterotoxins as immune stimulants in chronic rhinosinusitis. Clin Allergy Immunol 20: 163-175.

8. Brook I, Foote PA, Hausfeld JN (2008) Increase in the frequency of recovery of methicillin-resistant Staphylococcus aureus in acute and chronic maxillary sinusitis. J Med Microbiol 57: 1015-1017.

9. Puglies A (2010) Methicillin-resistant Staphylococcus aureus and chronic sinusitis. The Internet Journal of Infectious Diseases 9.

10. Gilmore KS, Gilmore MS, Sahm DF (2008) Methicillin Resistance in Staphylococcus aureus (chapter 12). In: Wax RG, Lewis K, Salyers AA, Taber H (eds.) Bacterial Resistance to Antimicrobials (2ndedn.). CRC Press, Taylor \& Francis Group, London, pp. 291-312.

11. Becker SS, Russell PT, Duncavage JA, Creech CB (2009) Current issues in the management of sinonasal methicillin-resistant Staphylococcus aureus. Curr Opin Otolaryngol Head Neck Surg 17: 2-5.

12. Suh JD, Kennedy DW (2011) Treatment Options for Chronic Rhinosinusitis. Proc Am Thorac Soc 8: 132-140. 
Citation: Al-Mayahie SMG, Al- Hamashee HTR, Hameed HM (2015) Prevalence and Antimicrobial Susceptibility of Methicillin-Resistant Staphylococcus aureus (MRSA) from Outpatients with Chronic Rhinosinusitis in Al-Kut/Wasit Province/lraq. J Bacteriol Parasitol 6: 230. doi:10.4172/2155-9597.1000230

Page 6 of 6

13. Brook I, Foote PA (2006) Isolation of methicillin resistant Staphylococcus aureus from the surface and core of tonsils in children. Int J Pediatr Otorhinolaryngol 70: 2099-2102.

14. Brown DFJ, Edwards DI, Hawkey PM, Morrison D, Ridgway GL, et al. (2005) Guidelines for the laboratory and susceptibility testing of methicillin-resistant Staphylococcus aureus (MRSA). J Antimicrob Chemother 56: 1000-1018.

15. Yıldız Ö, Çoban AY, Şener AG, Coşkuner SA, Bayramoğlu G, et al. (2014) Antimicrobial susceptibility and resistance mechanisms of methicillin resistant Staphylococcus aureus isolated from 12 Hospitals in Turkey. Ann Clin Microbiol Antimicrobiol 13: 44.

16. Warren DK, Liao RS, Merz LR, Eveland M, Dunne WM (2004) Detection of methicillin-resistant Staphylococcus aureus directly from nasal swab specimens by a real-time PCR assay. J Clin Microbiol 42: 5578-5581.

17. Forbes BA, Sahm DF, Weissfeld AS (2002) Bailey \& Scott's Diagnostic Microbiology (1thedn.) Mosby Inc, USA.

18. Ruzickova V, Voller J, Pantucek R, Perase P, Doskar J (2005) Multiplex PCR for detection of three exfoliative toxin serotype genes in Staphylococcus aureus. Folia Microbio 50: 499-502.

19. (2010) Clinical and Laboratory Standards Institute: Performance Standards for Antimicrobial Susceptibility Testing; Twentieth Informational Supplement, M100-S20.

20. Murakami K, Minamide W, Wada K, Nakamura E, Teraoka H, et al. (1991) Identification of methicillin-resistant strains of staphylococci by polymerase chain reaction. J Clin Microbiol 29: 2240-2244.

21. Ross SM (2009) Introduction to probability and statistics for Engineers and Scientists (4thedn.). Elsevier, London.

22. Lafi MAK, Auid AH, AL-Mawla SOG (2013) Diclofenac-cefoxitin double-disk method is a novel tool for phenotypic detection of methicillin resistant Staphylococcus aureus: a preliminary report. Anb Med J 11: 47-54.
23. Mohammed SM (2011) Use of cefoxitin as indicator for detection of Methicillin Resistant Staphylococcus aureus. Baghdad Science Journal 8: 947-955.

24. Fadhel AN, Abureesha RA, Al-azzawi RH (2013) Prevalence of S epidermidis and S. aureus and their biofilm ability among Iraqi patients suffering from urinary tract infection. Iraqi Journal of Science 54: 547-552.

25. Ologe FE, Nwabuisi C (2003) Bacteriology of chronic sinusitis in Ilorin, Nigeria. Afr J Clin Exp Microbiol 4: 91-97.

26. Niederfuhr A, Kirsche H, Deutschle T, Poppert S, Riechelmann H, et al. (2008) Staphylococcus aureus in nasal lavage and biopsy of patients with chronic rhinosinusitis. Allergy 63: 1359-1367.

27. Dancer SJ (2001) The problem with cephalosporins. J Antimicrob Chemother 48: 463-478.

28. Sachithanandam ST (2014) Rising Methicillin-Resistant Staphylococcus aureus Infections in Ear, Nose, and Throat Diseases. Case Reports in Otolaryngology 2014.

29. Manarey CRA, Anand VK, Huang C (2004) Incidence of methicillinresistant Staphylococcus aureus causing chronic rhinosinusitis. Laryngoscope 114: 939-941.

30. Didier JP, Villet R, Huggler E, Lew DP, Hooper DC, et al. (2011) Impact of ciprofloxacin exposure on Staphylococcus aureus genomic alterations linked with emergence of rifampin resistance. Antimicrob Agents Chemother 55: 1848-1852.

31. Al-Hassnawi HH, Al-Charrakh AH, Al-Khafaj JK (2012) Antibiotic resistance patterns of community acquired methicillin resistance Staphylococcus aureus (CA-MRSA) in Al-Hilla/ Iraq. Kerbala Journal of Pharmaceutical Sciences 10: 91-102. 